\section{Microbiological evaluation of ready-to-eat iceberg lettuce during shelf-life and effectiveness of household washing methods}

\author{
Daniela Bencardino, ${ }^{1,2}$ \\ Luca Agostino Vitali, ${ }^{2}$ \\ Dezemona Petrelli ${ }^{1}$
}

${ }^{1}$ School of Biosciences and Veterinary

Medicine, and ${ }^{2}$ Microbiology Unit,

School of Pharmacy, University of

Camerino, Italy

\begin{abstract}
The aim of this study was to assess the microbiological quality of ready-to-eat (RTE) iceberg lettuce. Our investigation was based on the consumption tendency of university students considered a target market for this product. A total of 78 RTE samples were collected from chain supermarkets and analysed for the enumeration of aerobic mesophilic count (AMC), Escherichia coli and the detection of Salmonella spp. and Listeria monocytogenes. All samples were negative for the presence of pathogens. The mean value of $\mathrm{AMC}$ at the beginning, in the middle and after the expiration date was: $6.88,8.51$ and $8.72 \log$ CFU g-1, respectively. The same investigation was performed on 12 samples of fresh iceberg lettuce samples. No pathogens were found and the mean value of AMC was lower than the RTE category (5.73 log $\mathrm{CFU} \mathrm{g}{ }^{-1} ; \mathrm{P}<0.05$ ). The effectiveness of 5 washing methods was determined on 15 samples of both fresh and RTE iceberg lettuce. Samples were washed for $15^{\circ}$ and $30^{\prime}$ in tap water $(500 \mathrm{~mL})$, tap water with $\mathrm{NaCl}(4 \mathrm{~g} / 500 \mathrm{~mL})$, tap water with bicarbonate $(8 \mathrm{~g} / 500 \mathrm{~mL})$, tap water with vinegar $(10 \mathrm{~mL} / 500 \mathrm{~mL})$ and tap water with chlorine-based disinfectant $(10 \mathrm{~mL} / 500$ $\mathrm{mL}$ ). A significant bacterial load reduction was recorded for vinegar and disinfectant after $30^{\prime}$ and 15', respectively. Overall, these results showed that RTE iceberg lettuce is more contaminated than the fresh product. Also, the consumption in the first few days of packaging and after washing with disinfectants reduces the risk for health consumers.
\end{abstract}

\section{Introduction}

A ready-to-eat (RTE) food is a product intended for the human consumption with- out cooking or other processing (Regulation EC No 2073/2005, European Commission). Consumer tendencies towards convenient foods increased the demand for RTE vegetables, especially leafy green salads (Abadias et al., 2008; de Oliveira et al., 2011). Notwithstanding their healthy and convenient aspects, the global growing consumption of RTE salads is dramatically related to several outbreaks of food infections (Mercanoglu and Halkman, 2011; Jung et al., 2014). Fresh produce can become contaminated at any point of chain production. Animals, soil, irrigation water and manure are the main sources of contamination in the field. The hydrophobicity of surface leave reduces the effectiveness of washing procedures resulting unable to reach microorganisms that colonise internal vegetable tissues. Moreover, nutrients released by leaf surface cells after cutting and slicing facilitate the microbial growth (Qadri et al., 2015). Cross-contamination during human and mechanical handling is an important risk factor affecting the final microbiological quality of the product. In light of this, the minimal processing not only is unable to eliminate the indigenous microflora of fresh vegetable but also increase it and provides many opportunities to bring in human pathogens (Jeddi et al., 2014). The cold-chain is an essential measure to ensure the quality and safety of RTE salads because refrigerated temperatures decrease the growth of some pathogens (Khalil and Frank, 2010). For this reason, the Regulation No 3746/2014 (Italian Regulation, 2014) specifies the temperature of production $\left(\mathrm{T}<14^{\circ} \mathrm{C}\right)$ and the temperature of raw material storage $\left(\mathrm{T}<8^{\circ} \mathrm{C}\right)$. Among the wide range of microbial hazards associated with RTE salads outbreaks, bacteria such as Escherichia coli (E. coli), Salmonella spp., Shigella spp., Listeria monocytogenes (L. monocytogenes) and Campylobacter jejuni are largely reported (Jung et al., 2014; Mercanoglu and Halkman, 2011). The overall aim of this study was to assess the microbiological quality of RTE iceberg lettuce, one of the most commonly consumed RTE salads in Italy. Iceberg lettuce belongs to Lactuca sativa family and it grows in spherical head. External crisp leaves, mainly exposed to contamination, are removed during postharvest operations increasing the risk of cross-contamination. Our objectives were to investigate the degree of contamination during shelf life and the reduction of bacterial load after domestic washing methods. To our knowledge, this is the first study evaluating the microbiological aspects of RTE iceberg lettuce commercialised in Italy.
Correspondence: Daniela Bencardino, School of Biosciences and Veterinary Medicine, University of Camerino, Via Gentile III da Varano, 62032 Camerino (MC), Italy. Tel: +39.0737.403286 - Fax: +39.0737.403290.

E-mail: daniela.bencardino@unicam.it

Key words: iceberg lettuce, microbial contamination, ready-to-eat, shelf-life, washing.

Contributions: the authors contributed equally. Conflict of interest: the authors declare no potential conflict of interest.

Funding: none.

Received for publication: 4 July 2017.

Revision received: 27 November 2017.

Accepted for publication: 27 November 2017.

This work is licensed under a Creative Commons Attribution-NonCommercial 4.0 International License (CC BY-NC 4.0).

CCopyright D. Bencardino et al., 2018 Licensee PAGEPress, Italy

Italian Journal of Food Safety 2018; 7:6913

doi:10.4081/ijfs.2018.6913

\section{Materials and Methods}

\section{Experimental design}

The investigation was based on consumption data collected from a survey targeting university students as a market segment for convenient foods. Considering the answers collected by interview, the microbiological analysis was performed at the beginning, in the middle and after the expiration date. Later, the effectiveness of household washing methods indicated by responders was evaluated through the determination of bacterial load reduction. The same investigation was also carried out on a representative number of fresh samples to get a global view of the microbiological quality of the two categories.

\section{Survey administration}

The survey was conducted to determine the consumption of RTE salads among 100 students of the University of Camerino, Italy. A random sample of 40 males and 60 females between the ages of 19 and 30 was interviewed.

\section{Sample collection}

Iceberg lettuce bags in modified atmosphere packaging (MAP) were collected from two chain supermarkets between May and July 2016 in Camerino. Three companies were considered and two bags for each one of them were collected $(n=30$ bags; 
$\mathrm{c}=60$ units) at 5 different collection times. As indicated by the Regulation EC No 2073/2005 (European Commission, 2005), the number of units were reduced considering satisfactory the procedure based on Hazard Analysis and Critical Control Point (HACCP) system applied by companies. All samples were collected at the beginning of their shelf-life, kept under refrigerated conditions and transported to the laboratory for the analysis. The second group of 30 samples was collected in the middle of their shelf-life and analysed. Instead, 9 samples $(\mathrm{n}=9 ; \mathrm{c}=18$ units) were collected at 3 different collection times and analysed after two days of the expiration date. Finally, 12 samples ( $c=24$ units) of fresh iceberg lettuce were collected from three companies at 4 different times and analysed as RTE samples.

\section{Microbiological analysis}

Ten grams of each sample was aseptically weighed in sterile bags, diluted in 90 $\mathrm{mL}$ of Maximum Recovery Diluent (MRD) and homogenised for 2 minutes using a stomacher (Model 400 circulator, Seward, UK). To determine the AMC, aliquots of decimal dilutions were analysed according to the standard culture method (UNI EN ISO 4833:2004). The acceptability of results was established in accordance with the limits set by the Regulation (EC) No 2073/2005 (European Commission, 2005). The detection of $E$. coli beta glucuronidase positive (UNI EN ISO 16649-2:2001), Salmonella spp. (UNI EN ISO 6579:2008) and L. monocytogenes (UNI EN ISO 11290-1:2005) was carried out in according to their ISO methods.

\section{Washing treatment and bacterial load reduction}

On the basis of data collected through our survey and those found in previous studies (de Oliveira et al., 2012; Nascimento et al., 2003; López-Gálvez et al., 2010), samples were washed through the immersion in tap water $(500 \mathrm{~mL})$; tap water $(500 \mathrm{~mL})$ with the addition of bicarbonate $(8 \mathrm{~g})$; tap water $(500 \mathrm{~mL})$ with $\mathrm{NaCl}$ $(4 \mathrm{~g})$; tap water $(500 \mathrm{~mL})$ with vinegar $(10$ $\mathrm{mL})$; tap water $(500 \mathrm{~mL})$ with a conventional chlorine-based disinfectant $(10 \mathrm{~mL})$.

A total of 15 samples ( $c=30$ units) of RTE iceberg lettuce from three companies and 15 samples ( $c=30$ units) of the fresh category were collected. All were kept under refrigerated conditions, transported to the laboratory, washed and analysed. Fresh samples were cut into triangles sections including the external, central and internal part of each head iceberg.

At first, the AMC of each sample and that of tap water used for each washing method were performed in order to calculate the potential bacterial load reduction. Twenty-five grams of all samples were washed for different immersion times $\left(\mathrm{t}_{0}=0\right.$ $\mathrm{s} ; \mathrm{t}_{1}=15 \mathrm{~min} ; \mathrm{t}_{2}=30 \mathrm{~min}$ ). After each washing time, the AMC was performed. For the $\mathrm{t}_{0}$ step, the sample was immediately rinsed after the immersion.

\section{Statistical analysis}

All samples were tested in duplicate and the bacterial counts were expressed as log CFU g-1 ${ }^{-1}$ Assuming a log-normal distribution, standard deviations and means were calculated. Independent t-test and one-way analysis of variance (ANOVA) were used to determine any statistically significant difference $(\mathrm{P}<0.05)$ among two or more than of two groups of data, respectively.

\section{Results}

\section{Results of survey}

Fifty-nine out of 100 students stated that they ate RTE salads. Of them, the $69 \%$ reported a consumption of RTE salad once a week. Concerning the washing methods, 26 (44\%) respondents revealed that they always wash the product before consumption. Specifically, 25 stated that they usually wash it just with water while one respondent indicated the addition of bicarbonate to water. None practised washing treatment for more of 10 minutes and the leaves are washed only once by 22 respondents, twice by 3 and more than twice by a single respondent. Twenty-four students (41\%) consumed the salad in the same day, 24 (41\%) within two days and the remaining $11(18 \%)$ in more than two days. A large portion of respondents $(77 \%)$ revealed the tendency to consume the product after the expiration date.

\section{Microbiological analysis of RTE ice- berg leaves.}

Table 1 summarises the results obtained from our analysis indicating the number of samples for each range of AMC value detected. The AMC of samples analysed at the beginning of their shelf-life ranged from 6.03 to $8.43 \log$ CFU g-1 ${ }^{-1}$ with an average of $6.88 \log \mathrm{CFU} \mathrm{g}^{-1}$. On the other hand, the samples analysed in the middle of their shelf-life had higher bacteria levels ranging from 6.04 to $9.26 \log \mathrm{CFU} \mathrm{g}^{-1}$, with an average of $8.51 \log$ CFU g ${ }^{-1}$. Counts recorded in the middle of shelf-life compared with those at the beginning of shelf-life increased by an average of $25 \%$. This difference was statistically significant $(\mathrm{P}<0.05)$. Comparing the means of microbial loads among the three companies, no significant differences were found (ANOVA, $\mathrm{P}=0.74$ ). The AMC values of samples analysed after the expiration date ranged from 6 to $10 \log \mathrm{CFU} \mathrm{g}^{-1}$, with an average of $8.72 \log \mathrm{CFU} \mathrm{g}^{-1}$ (Table 1). All samples, with one exception, were recorded with a very high bacterial load ( $>8 \log \mathrm{CFU}$ $\mathrm{g}^{-1}$ ) from 1 to $3 \log$ higher than the allowed AMC. All RTE iceberg lettuce samples were negative for the presence of $L$. monocytogenes and Salmonella spp. whereas E. coli was under the detection limit of $10 \mathrm{CFU} \mathrm{g}^{-1}$.

\section{Microbiological analysis of fresh ice- berg lettuce samples}

Also in fresh iceberg samples, no presence of L. monocytogenes, Salmonella spp. and $E$. coli $\left(<10 \mathrm{CFU} \mathrm{g}^{-1}\right)$ was observed. AMC ranged from the minimum value of $4.7 \log$ CFU g-1 to the maximum of $7.5 \log$

Table 1. Aerobic mesophilic count of ready-to-eat iceberg samples during the shelf-life period.

\begin{tabular}{lccc} 
Range $^{a}$ & At the beginning of shelf-life & In the middle of shelf-life & After the expiration date \\
$10^{5}-10^{6}$ & 2 & ND & ND \\
$10^{6}-10^{7}$ & 13 & 5 & 1 \\
\hline $10^{7}-10^{8}$ & 11 & 7 & ND $^{\mathrm{b}}$ \\
$10^{8}-10^{9}$ & 4 & 17 & 4 \\
\hline $10^{9}$ & $\mathrm{ND}$ & 1 & 4 \\
\hline
\end{tabular}

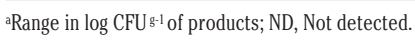


CFU g-1, with the medium of $5.73 \log$ CFU $\mathrm{g}^{-1}$. In the majority of the samples, the counts ranged between 5 and $6 \log \mathrm{CFU} \mathrm{g}{ }^{-1}$, only one sample reported a count of $7 \mathrm{log}$ CFU g-1 ${ }^{-1}$ The bacterial load of fresh samples was lower of $1.2 \operatorname{logs}$ than RTE samples.

\section{Effectiveness of washing treatment in RTE salad leaves}

Figure 1 summarizes the results obtained from the washing treatments used for RTE salad leaves. For each one, the AMC of unwashed leaves was indicated as $100 \%$. Only in the case of water, no bacterial load reduction was registered before 30 minutes of washing and the percentage of reduction was very low (2\%). A similar percentage was obtained by washing the leaves in water with $\mathrm{NaCl}$ and in water with bicarbonate (91\% and 94\%, respectively). However, the reduction of bacterial load after 15 minutes of washing in water and bicarbonate was higher than in water and $\mathrm{NaCl}(3 \%$ and $1 \%$, respectively), but this difference was not significant $(\mathrm{P}>0.05)$. The washing treatment based on water and vinegar was more efficient than the treatments considered above. Finally, the samples washed in water with the addition of chlorine-based disinfectant showed a reduced load $(81 \%)$ already after a quick washing cycle $\left(\mathrm{t}_{0}\right)$. A consistent reduction (85\%) was obtained between 15 and 30 minutes of washing. Hence, the washing treatments based on vinegar and disinfectant significantly reduced the AMC of RTE samples.

\section{Effectiveness of washing treatment in fresh salad leaves}

For the leaves washed in water, a weak reduction $(4 \%)$ of the bacterial load was detected and only after 30 minutes (Figure 2). Comparing the AMC of leaves washed in water with $\mathrm{NaCl}$ and that of leaves washed in water with bicarbonate, similar results were obtained. During the first 15 minutes of washing, no reduction was detected in both treatments. Between 15 and 30 minutes of washing, the total count decreased by $2 \%$ (from $96 \%$ to $94 \%$ ) in water with $\mathrm{NaCl}$ and by $4 \%$ (from $96 \%$ to $92 \%$ ) in water with bicarbonate. The washing in water with vinegar showed a higher reduction if compared to the treatments with water plus bicarbonate and water alone. Consistently, the leaves reported a $22 \%$ reduction in the initial total count after 30 minutes of washing. The AMC of the fresh iceberg was significantly reduced washing them in water with chlorine-based disinfectant

\section{Discussion}

Nowadays several studies on microbiological contamination of RTE vegetables are carried out (Jeddi et al., 2014; Erkan and Vural, 2008). This is the first work focused on RTE iceberg lettuce commercialised in Italy. Our survey, targeted to university students, confirmed the high consumers' demand of RTE salads by young people. The increased consumption of RTE foods, including salads, is strongly associated with the reduction of time spent by modern society for meal preparation (Buckley et al., 2007).

In 2013, the European Food Safety Authority (EFSA, 2013) examined the risk from leafy green salads observing that many outbreaks were caused by their microbial contamination. The guidelines provided by the Public Health Laboratory Service (2000) indicates that no mandatory unacceptable AMC reference limits are defined for the RTE vegetables. However, the poor hygienic level of chain production is indicated by the exceeding of the unsatisfactory limit defined as $\geq 10^{7}$ (PHLS, 2000). Our data confirmed the results of other studies (Chen and Godwin, 2012; Jeddi et al., 2014; Erkan and Vural, 2008), where all collected lettuce samples were contaminated by a high bacterial load. No significant difference in terms of contamination was found among the commercial brands highlighting the same hygienic level. Noteworthy, RTE samples showed higher AMC values than fresh category pointing to the additional contamination of product during the processing. Concerning this issue, De Giusti et al. (2010) provided the evidence that preventive strategies such as the observation of both good agricultural and manufacturing practices (GAPs; GMPs) could improve the microbiological quality of RTE vegetables. Generally, the improvement of good hygienic practices during processing could be fundamental not only to increase the microbiological quality of the products but also to extend their shelf-life.

In compliance with the Regulation EC No 2073/2005 (European Commission, 2005), no Salmonella spp. and L. monocytogenes were detected in any samples (RTE and fresh iceberg leaves). This was a positive result as the presence of these pathogens is an unacceptable criterion for food consumption. Our data are consistent with those of previous studies (Almualla et al., 2010; De Giusti et al., 2010) where Salmonella spp. and L. monocytogenes were not detected in analysed samples. Conversely, these results are conflicting with the high rate of Salmonella spp. (46.7\%) reported by Bruno et al. (2005) in Brazil as well as with the high rate $(22.5 \%)$ of $L$. monocytogenes reported by Ponniah et al. (2010) in Malaysia.

Surprisingly, no occurrence of E. coli was detected in our investigation. In spite of this result, E.coli has been observed with a high percentage in other studies: $30 \%$ by Prado et al. (2008), 53.1\% by de Oliveira et

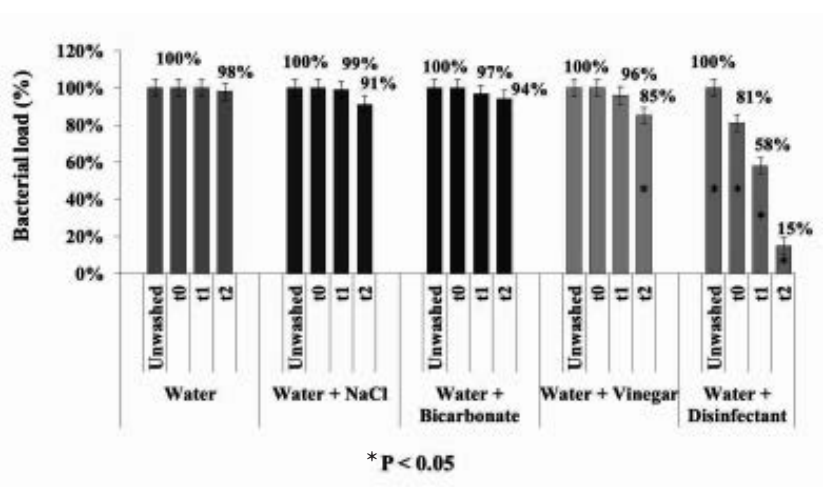

Figure 1. Effect of different washing procedures on the reduction of bacterial load in RTE iceberg lettuce.

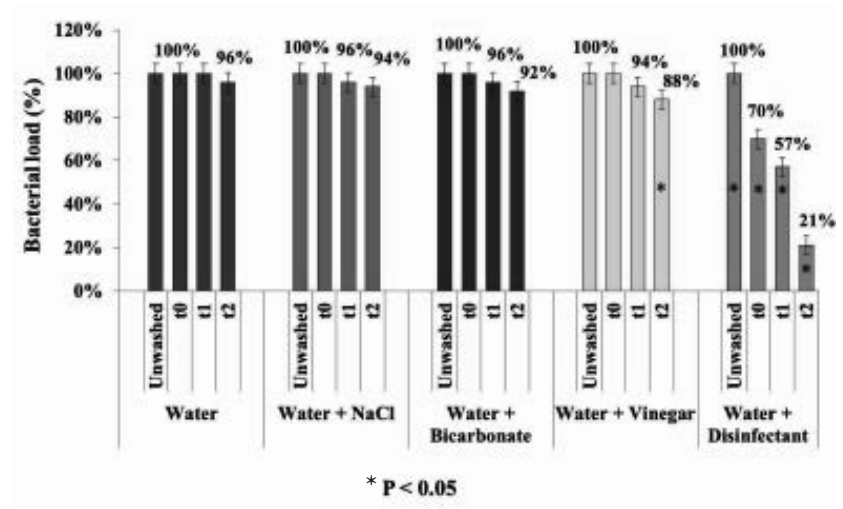

Figure 2. Effect of different washing procedures on the reduction of bacterial load in fresh iceberg lettuce. 
al. (2011). Many outbreaks resulted from the consumption of leafy vegetables contaminated by the presence of E. coli in manure and soil (Wendel et al., 2009). Cracks and intercellular spaces of vegetables are colonised by many pathogens (Mercanoglou and Halkman, 2011; Jung et al., 2014) and prevention measures to reduce microbial contamination are available.

Washing and sanitising efficiencies can be influenced by various factors such as production surface, water quality, sanitizer used and contact time (De Giusti et al., 2010; Parish et al., 2003). According to literature, warm water is not able to reduce bacterial load and it could facilitate the growth of pathogens such as L. monocytogenes (Li et al., 2002). Our data revealed that the effectiveness of washing varied according to the method and to the immersion time. The most common wash based only on tap water resulted in being unable to detach bacteria from leaves as well as those with the addition of $\mathrm{NaCl}$ and bicarbonate. This result is consistent with that reported by a Brazilian work analysing washing procedures in some restaurants (de Oliveira et al., 2012) and also with that of Neto et al. (2012) analysing the microbial quality of lettuce obtained from different cropping systems. On the other hand, the wash treatment based on vinegar seems to be more efficient than others, but only after a long time of immersion. In spite of its ability to reduce bacterial load, vinegar may also be responsible of the browning effect on leaves reducing the appeal of the product (de Oliveira et al., 2012). The combination of disinfectant and time of immersion showed an increased effect on the total bacterial load reduction. Nascimento et al. (2003) and López-Gálvez et al. (2010) reported a similar great reduction of bacterial load after disinfectant use. In the present work, the differences in bacterial load comparing the washing times were not statistically significant $(\mathrm{P} \geq 0.05)$ irrespective of the washing method, the only exception represented by the use of disinfectant. As expected, a relevant decline in bacterial counts was obtained by washing with disinfectant for a long time (30 minutes).

\section{Conclusions}

This study presented a general assessment of the microbiological quality of RTE iceberg lettuce commercialised in Italy. The research clearly evidenced that the RTE product has higher contamination level than the fresh produce. Hence, industrial processing is an important additional source of microbial contamination. Thus, the improvement of Good Agricultural and Manufacturing Practices (GAPs; GMPs) by producers is necessary to ensure food safety. The consumption of RTE iceberg lettuce during the first period of shelf-life and after washing with disinfectants minimise the risk for human health. Further studies analysing these microbial aspects can provide consumers with useful information about the use of RTE iceberg lettuce at its highest quality.

\section{References}

Abadias M, Usall J, Anguera M, Solsona C, Vinas I, 2008. Microbiological quality of fresh, minimally-processed fruits and vegetables, and sprouts from retail establishment. Int $\mathrm{J}$ Food Microbiol 123:121-9.

Almualla NA, Laleye LC, Abushelaibi AA, Al-Qassemi RA, Wasesa AA, Baboucarr J, 2010. Aspects of the microbiological quality and safety of ready-to-eat foods in sharjah supermarkets in the United Arab Emirates. J Food Prot 73:1328-31.

Bruno LM, Queiróz AAM, Andrade APC, Vasconcelos NM, Borges MF, 2005. Microbiological evaluation of vegetables and fruits minimally processed marketed in Fortaleza (CE). Bol Cent Pesqui Process Aliment 23:75-84.

Buckley M, Cowan C, McCarthy M, 2007. The convenience food market in Great Britain: convenience food lifestyle (CFL) segments. Appetite 49:600-17.

Chen FC, Godwin SL, 2012. The bacteria content of bagged, pre-washed greens as related to the best if used by date. JFDRS 43:1-6.

De Giusti M, Aurigemma C, Marinelli L, Tufi D, De Medici D, Di Pasquale S, De Vito C, Boccia A, 2010. The evaluation of the microbial safety of fresh readyto-eat vegetables produced by different technologies in Italy. J Appl Microbiol 109:996-1006.

de Oliveira ABA, Ritter AC, Tondo EC, Cardoso MI, 2012. Comparison of different washing and disinfection protocols used by food services in Southern Brazil for lettuce (Lactuca sativa). FNS 3:28-33.

de Oliveira MA, de Souza VM, Morato Bergamini AM, Pereira De Martinis EC, 2011. Microbiological quality of ready-to-eat minimally processed vegetables consumed in Brazil. Food Control 22:1400-3.

European Food Safety Authority, 2013. Scientific Opinion on the risk posed by pathogens in food of non-animal origin. Part 1 (outbreak data analysis and risk ranking of food/pathogen combinations). EFSA J 11:1-3025. Available from: http://onlinelibrary.wiley.com/ doi/10.2903/j.efsa.2013.3025/abstract.

Erkan ME, Vural A, 2008. Investigation of microbial quality of some leafy green vegetables. J Food Technol 6:285-8.

European Commission, 2005. Regulation of the European Commission of 15 November 2005 on microbiological criteria for foodstuffs, 2073/2005/EC. In: Official Journal, L 338/1, 22/12/2005.

ISO, 2001. Microbiology of food and animal feeding stuffs. Horizontal method for the enumeration of beta-glucuronidase-positive Escherichia coli. Part 2: Colony-count technique at 44 degrees C using 5-bromo-4-chloro-3indolyl beta-D-glucuronide. ISO Norm 16649:2001. International Standardization Organization ed., Geneva, Switzerland

ISO, 2004. Microbiology of food and animal feeding stuffs. Horizontal method for the enumeration of microorganisms: colony count technique at $30^{\circ} \mathrm{C}$. ISO Norm 4833:2004. International Standardization Organization ed., Geneva, Switzerland.

ISO, 2005. Microbiology of food and animal feeding stuffs. Horizontal method for the detection and enumeration of Listeria monocytogenes. Part 2: Enumeration method. ISO Norm 11290-2:2005. International Standardization Organization ed., Geneva, Switzerland.

ISO, 2008. Microbiology of food and animal feeding stuffs. Horizontal method for the detection of Salmonella spp. ISO Norm 6579:2008. International Standardization Organization ed., Geneva, Switzerland.

Italian Regulation, 2014. Regulation of the Italian Government of 20 June 2014. Implementation of art.4 of law 13th May 2011 no.77, laying down disposition to preparation, packaging and distribution of ready-to-eat vegetables. In Official Journal, DM n. 186, 12/08/2014.

Jeddi MZ, Yunesian M, Gorji ME, Noori N, Pourmand MR, Khaniki GRJ, 2014. Microbial evaluation of fresh, minimally-processed vegetables and bagged sprouts from chain supermarkets. J Health Popul Nutr 32:391-9.

Jung Y, Jang H, Matthews KR, 2014. Effect of the food production chain from farm practices to vegetable processing on outbreak incidence. Microb Biotechnol 7:517-27. 
Khalil RK, Frank JF, 2010. Behavior of Escherichia coli O157:H7 on damaged leaves of spinach, lettuce, cilantro, and parsley stored at abusive temperatures. J Food Prot 73:212-20.

Li Y, Brackett RE, Chen J, Beuchat LR, 2002. Mild heat treatment of lettuce enhances growth of Listeria monocytogenes during subsequent storage at $5^{\circ} \mathrm{C}$ or $15^{\circ} \mathrm{C}$. J App Microbiol 92:269-75.

López-Gálvez F, Gil MI, Truchado P, Selma MV, Allende A, 2010. Cross-contamination of fresh-cut lettuce after a shortterm exposure during pre-washing cannot be controlled after subsequent washing with chlorine dioxide or sodium hypochlorite. Food Microbiol 27:199-204.

Mercanoglu TB, Halkman AK, 2011. Do leafy green vegetables and their readyto-eat [RTE] salads carry a risk of foodborne pathogens?. Anaerobe 17:286-7.

Nascimento MS, Catanozi M, Silva KC, 2003. Effects of different disinfection treatments on the natural microbiota of lettuce. J Food Prot 66:1697-700.

Neto NJG, Pessoa RML, Nunes Queiroga IMN, Magnani M, de Sousa Freitas FI, de Souza EL, Maciel JF, 2012. Bacterial counts and the occurrence of parasites in lettuce (Lactuca sativa) from different cropping systems in Brazil. Food Control 28:47-51.

Parish ME, Beuchat LR, Suslow TV, Harris LJ, Garrett EH, Farber JN, Busta FF, 2003. Methods to reduce/eliminate pathogens from fresh and fresh-cut produce. Compr Rev Food Sci Food Saf 2:161-73.

Ponniah J, Robin T, Pale MS, Radu S, Ghazali FM, Kqueen CY, Nishibuchi M, Nakaguchi Y, Malakar PK, 2010. Listeria monocytogenes in raw salad vegetables sold at retail level in Malaysia. Food Control 21:774-8.

Prado SPT, Ribeiro EGA, Capuano DM, Aquino AL, Rocha GM, Bergamini AMM, 2008. Microbiological and parasitic quality and labelling adequacy of minimally processed vegetables com- mercialized in Ribeirão Preto, SP/Brazil. Rev Inst Adolfo Lutz 67:221-7.

Public Health Laboratory Service, 2000. Guidelines for the microbiological quality of some RTE foods sampled at the point of sale. Comm Dis Publ Health 3:137-63.

Qadri OS, Yousuf B, Srivastava AK, 2015. Fresh-cut fruits and vegetables: Critical factors influencing microbiology and novel approaches to prevent microbial risks-A review. Cogent food agric 1:111.

Wendel AM, Johnson DH, Sharapov U, Grant J, Archer JR, Monson T, Koschmann C, Davis JP, 2009. Multistate outbreak of Escherichia coli O157:H7 infection associated with consumption of packaged spinach, AugustSeptember 2006: the Wisconsin investigation. Clin Infect Dis 48:1079-86. 